\title{
Knowledge and quality of life among Indonesian students during the COVID-19 pandemic
}

\author{
Prasojo Pribadi ${ }^{1}$, Lolita Lolita ${ }^{2}$, Rayi Citra Ayu Pangestuti ${ }^{3}$, Heni Lutfiyati ${ }^{4}$, Silvia Mareti $^{5}$, Azis \\ Ikhsanudin 6 \\ 1,3,4 Department of Pharmacy, Universitas Muhammadiyah Magelang, Magelang, Central Java, Indonesia \\ ${ }^{2,6}$ Faculty of Pharmacy, Universitas Ahmad Dahlan, Special District of Yogyakarta Province, Indonesia \\ ${ }^{2}$ Research Division of Clinical Pharmacology, The First Affiliated Hospital of Nanjing Medical University, Jiangsu \\ Province, P.R. China \\ ${ }^{5}$ Academy of Nursing, Pangkal Pinang, Bangka Belitung Province, Indonesia \\ ${ }^{2,6}$ Department of Pharmaceutics, School of Pharmacy, China Pharmaceutical University, Jiangsu Province, P.R. China
}

\begin{abstract}
Article Info
Article history:

Received Jan 9, 2021

Revised Mar 2, 2021

Accepted Mar 14, 2021

Keywords:

COVID-19

Indonesia

Knowledge

Quality of life

ABSTRACT

The increasing of online coronavirus disease-2019 (COVID-19) informationsharing in digital media can contribute to the emergence of misinformation in public. Much insufficient knowledge will confuse public understanding and affect their quality of life. The study purposed to assess the knowledge and its influence on Indonesian students' quality of life during the COVID-19 crisis. A cross-sectional study was conducted between October and December 2020 by distributing online questionnaires. The data analysis was run through the Spearman correlation method by using SPSS version 21.0. A total of 200 respondents aged over 17 years were recruited using a snowball sampling technique. Most study respondents had insufficient knowledge about COVID-19, 23\% of them had moderate knowledge, and only $17.5 \%$ had high knowledge. They obtained primary sources of COVID-19 information from social media platforms. The results showed that health science students have a better understanding than social science students $(\rho<0.001)$. The level of knowledge has a significant associated with psychological domain $(\rho=0.020)$, environmental domain $(\rho=0.046)$, and overall quality of life $(\rho=0.047)$. Thus, the media control center is vital to encounter valid information in providing better knowledge and quality of life during a pandemic.
\end{abstract}

This is an open access article under the CC BY-SA license.

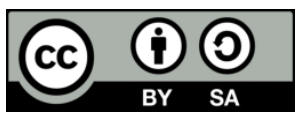

Corresponding Author:

Lolita Lolita

Faculty of Pharmacy

Universitas Ahmad Dahlan

Prof Dr Soepomo Warungboto Umbulharjo, Yogyakarta, Indonesia

Email: lolita@pharm.uad.ac.id; lolita_ur@yahoo.com

\section{INTRODUCTION}

Coronavirus disease-2019 (COVID-19) has become a global health issue highlighted in the local and international media [1]. The virus has spread very widely in nearly every country globally since it was first published in Wuhan, Hubei, China, in December 2019. The number of new COVID-19 infections has increased every day [2]. According to WHO data, 71,051,805 confirmed cases of COVID-19, including 1,608,648 deaths in 216 countries worldwide, have been documented worldwide since December 14, 2020 [3]. The US, India, and Brazil are in the top three COVID-19 rankings worldwide. Meanwhile, Indonesia moved from 3rd to 2nd, with COVID-19 being the most confirmed cases in Southeast Asia after India [4]. 
Severe acute respiratory syndrome coronavirus type 2 (SARS-CoV-2) is responsible for COVID-19 infection [5]. Although its level of virulence was low, COVID-19 seems to have a higher transmission level than other members of the coronavirus families, such as SARS-CoV and Middle East respiratory syndrome (MERS-CoV). A few numbers of awareness of COVID-19 prevention plays a role in uncontrolled coronavirus spread. The absence of a potential vaccine and specific antivirus for COVID-19 is another major challenge in controlling the pandemic [6].

In COVID-19 pandemic control efforts, knowledge is an important factor to be considered. Lack of knowledge can affect the behavior of individuals adversely, leading to indifference to their health. The existence of unproven information related to COVID-19 could also stimulate various misunderstandings. Data from the Indonesian Ministry of Communication and Information shows that there are 800,000 hoaxes throughout Indonesia, 554 associated with the causes, distribution, prevention, and treatment of COVID-19. It extends to over 1,209 Facebook, Instagram, Twitter, or Youtube platforms [7], [8]. Deviation from spreading news, whether intentionally or unintentionally, can have a negative public impact. The knowledge gained from invalid sources can influence people's inappropriate behavior facing the COVID-19 pandemic [9]. Furthermore, it will trigger negative emotions, stress, and depression, leading to decreased life quality [10].

Several studies examining COVID-19 related knowledge have been conducted among Indonesian populations. However, those studies' respondents were non-health students [11], [12] and the general public [13], [14]. To the best of our knowledge, research showed the relationship between knowledge and quality of life in health and non-health students has not been carried out before. Nevertheless, our previous study examined COVID-19-related knowledge before outbreaks in Indonesia, which found 83.8\% of respondents had a high level [15]. In the meantime, Eduarda et al. reported that there was a deterioration in the quality of life (QOL) of populations in countries with COVID-19 cases [16]. To date, few studies have demonstrated the knowledge and quality of life level in Indonesian students during the pandemic. Many quality of life research in Indonesia is limited to patients with chronic diseases such as diabetes mellitus, tuberculosis, and cancer [16], [17]. Continuous dissemination, strict isolation measures in the pandemic will affect student's learning process. It also does not rule out the possibility of depression, distress, and influencing their quality of life. Hence, our study examines the relationship between students' knowledge and quality of life during the COVID-19 pandemic.

\section{RESEARCH METHOD}

\subsection{Study design and data collection}

The research design was an observational study with a cross-sectional survey approach and conducted with Google platform online questionnaire from October to December 2020. The sample size was calculated online by Select Statistical Services. The minimum required sample size for a $99 \%$ confidence level with a margin error of $10 \%$ was 166 . A total of 200 respondents were taken by using the snowball sampling technique. Respondents were identified with eligible criteria: 1) college students aged over 17 years; 2) living in Central Java, Indonesia during the COVID-19 pandemic; and 3) willing to give informed consent. Respondents who did not completely respond to one or more items in the online survey were excluded. In our study, respondents were classified into health science and social science students. The student group clustering was intended to facilitate statistic analysis in comparing the obtained data.The online questionnaire was distributed through social media platforms with the attached consent form. This study has been approved by the Aisyiyah University Ethics Committee (No 1305/KEP-UNISA/IV/2020).

\subsection{Research instrument}

The questionnaire consists of three segments. In the first section, we collected the respondents' socio-demographic profile based on age, gender, student type, education level, university type, history of chronic disease, supplement, and health condition. The second section is COVID-19 knowledge measurement, and the third section is quality of life measurement. A structure knowledge questionnaire was adapted and modified from previous research conducted by Zhong et al. [17] and Alzoubi et al. [18]. We modified the 13 questionnaire items to involve diagnosis, symptom, transmission, cause, prevention, treatment, and risk factor towards COVID-19. Respondents who answered "Yes" were given 1 point while "No/I don't know" was given 0 points. The score of the total answer is calculated from 0-13 points. If the total right answer is $<55 \%$, the respondent is categorized as having low knowledge. The participant who scored between $56 \%$ to $75 \%$ defined that they have moderate knowledge. A high level of knowledge if their correct response answer is $\geq 76 \%$. The knowledge questionnaire's reliability has been measured using a Cronbach Alpha Coefficient with the value of 0.831 . 
The quality of life questionnaire was adopted from the World Health Organization Quality of Life (WHOQOL)-BREF Indonesian version [19]. This questionnaire consists of four domains, including the physical domain, psychological domain, social domain, and environmental domain, covered in 26 QOL question items. All of the domains in the Indonesian version of WHOQOL-BREF met the reliability criteria, with the value of Cronbach's alpha was 0.983. There are two additional general questions for overall QOL, and health satisfaction in WHOQOL-BREF include "how would you rate your quality of life?" and "how satisfied are you with your health?". Respondents answered the questionnaire by choosing answers using a five-point rating scale, favourable (positive) and unfavourable (negative) assessment categories.

\subsection{Data analysis}

Descriptive analysis was used to analyze the frequency of data on socio-demographic characteristics, student knowledge level, and the student's quality of life during the COVID-19 pandemic. The Kolmogorov-Smirnov test was used to determine the data normality. This study found that the whole variables data have not normal distribution. Therefore, Spearman correlation test was performed to determine the association between knowledge level and each quality of life domain. The independent t-test was also performed to determine the significant difference between the mean scores of knowledge in health science and social science students. The difference between two variables is statistically significant if the calculated $\rho$-value less than 0.05. Data were analyzed using SPSS version 21.0.

\section{RESULTS AND DISCUSSION}

A total of 200 respondents completed all survey questions and were recruited into the analysis. The main socio-demographic respondent characteristics are described in Table 1. The majority of the study population was female (78.5\%), aged between 17-25 years (98.5\%), health science students $(62.5 \%)$, bachelor education level (85\%), and study in private universities $(88.5 \%)$. Based on Table 1, although most respondents did not have any efforts to prevent COVID-19 by consuming supplements or vitamins, they stated that their health status during the COVID-19 pandemic was healthy (92.5\%) and had no chronic illness history $(98.6 \%)$.

Table 1. Demographic characteristic of the respondents

\begin{tabular}{lc}
\hline \multicolumn{1}{c}{ Variables } & Total (Percentage) \\
$\mathrm{n}(\%)$
\end{tabular}


Regarding student's knowledge levels, $59.5 \%$ of respondents had "low" knowledge, $23 \%$ had "moderate" knowledge, and $17.5 \%$ had "high" knowledge as shown in Figure 1. This study concluded that most respondents had "low" knowledge about COVID-19 from the aspects of symptoms, diagnosis, transmission, causes, prevention, treatment, and risk factor.

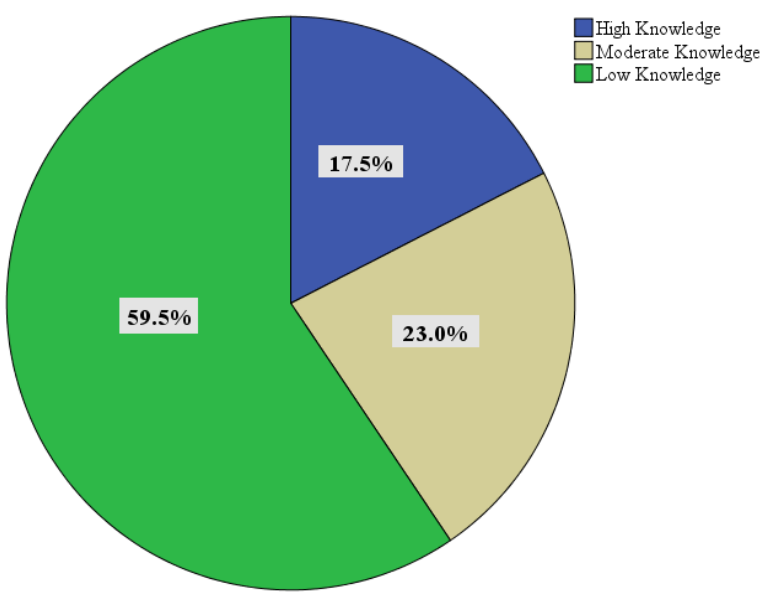

Figure 1. Student's level of knowledge

Table 2 shows that the health science student's overall mean score of knowledge was $7.57 \pm 2.33$, while the social science students were 6.07 \pm 2.36 . Based on the independent T-test result, we can conclude that health students have significantly higher scores of COVID-19 knowledge than social students $(\mathrm{p}<0.001)$. This finding is in line with a study conducted by Kistan et al. and Sahar et al. which stated that health students' knowledge about the prevention of COVID-19 in Indonesia was classified as good [20], [21]. A study was done by Alzoubi et al. also reported that health science students had a high knowledge of COVID19, while social science students had low knowledge [18]. Previous studies have also reported the level of knowledge of Indonesian students based on education majors. A study found that public health science students had higher knowledge scores than technology, socials, and humanities students [11]. A possible explanation might be that health science students rely more on a self-learning, science, and social networks [22]. Our present study reported that health science students had better knowledge of treatment, mode of transmission, and diagnosis of COVID-19. They responded correctly to questions that antibiotics, tea, and betel leaf are not effective in treating the infection with COVID-19. Social sciences students still believe that COVID-19 can be treated with antibiotics, tea, and betel leaves.

Table 2. The mean score of knowledge of health and social science students with independent t-test analysis

\begin{tabular}{ccc}
\hline Students type & Mean \pm SD & $\rho$-value \\
\hline Health science & $7.57 \pm 2.33$ & $<0.001$ \\
Social science & $6.07 \pm 2.36$ & \\
\hline
\end{tabular}

Figure 2 explains the various sources of information obtained by respondents regarding knowledge about COVID-19. Social media is the most common source $(61.5 \%)$, followed by television (18\%), websites $(11.5 \%)$, health workers $(7.5 \%)$, and friends/family/colleagues $(0.5 \%)$. These results were in line with those reported that the main sources of knowledge were social media, internet, and television [18]. Besides, a specific study related to COVID-19 knowledge has been conducted among Indonesian undergraduate students. Those studies indicated that as many as $38 \%$ of respondents frequently use social media platforms to obtain COVID-19 update information. It concluded that social media had become the most popular source of COVID-19 information [23].

As a source of information, the media has a vital role in public perceptions and responses about COVID-19 [24]. Integrating social media into COVID-19 preparedness community activities could build their resilience [25]. However, several misinformation and hoaxes regarding COVID-19 had emerged and repeated on social media [26]. To date, society still has some non-uniform knowledge of COVID-19's origin, transmission, and prevention. Our current study found that most respondents, both students of health and 
social sciences, responded incorrectly to the disinfectants' spraying on the body. One emerging public misinformation was spraying disinfectants across the body could kill the novel coronavirus [27]. WHO, though, said it could burn mucous membranes of the body [28]. Nevertheless, most respondents understood that masks and washing hands could prevent COVID-19 transmission. There has been a significant relationship between public knowledge and compliance with the use of masks regarding to prevent COVID19 [29], [30].

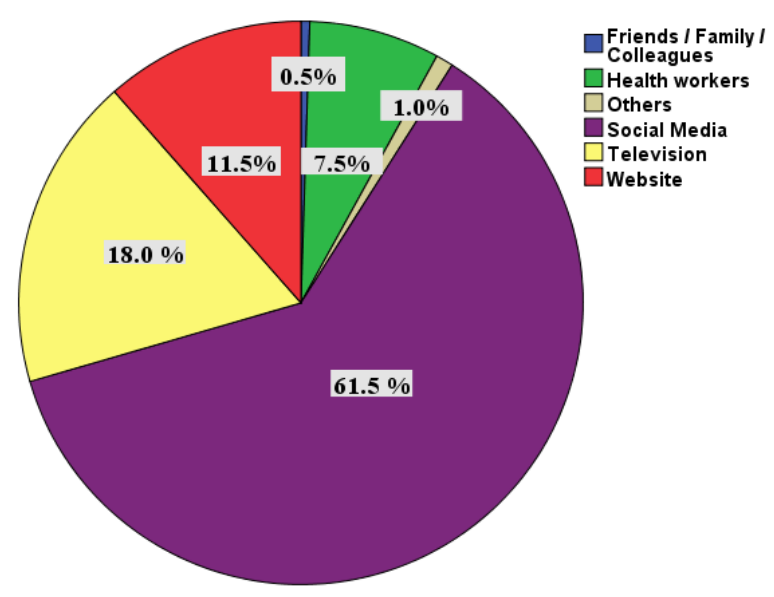

Figure 2. Reported source of knowledge about COVID-19

Table 3 describes that most of the respondents considered that the quality of life was good in the quality of life domain as shown: physical (48\%), psychological (47.5\%), and environmental $(47.5 \%)$. However, most respondents rated their quality of life as moderate in the social domain (38\%).

Table 3. Student's quality of life domain

\begin{tabular}{cccccc}
\hline \multirow{2}{*}{ Quality of life's domain } & \multicolumn{4}{c}{$\mathrm{n}(\%)$} \\
& Very bad & Bad & Moderate & Good & Very good \\
\hline Physical & $0(0)$ & $4(2)$ & $32(16)$ & $96(48)$ & $68(34)$ \\
Psychological & $1(0.5)$ & $7(3.5)$ & $35(17.5)$ & $95(47.5)$ & $62(31)$ \\
Social & $3(1.5)$ & $12(6)$ & $76(38)$ & $63(31.5)$ & $46(23)$ \\
Environmental & $1(0.5)$ & $7(3.5)$ & $35(17.5)$ & $95(47.5)$ & $62(31)$ \\
\hline
\end{tabular}

Regarding on the Spearman correlation test in Table 4, this study stated that there was a significant relationship between the level of knowledge towards the psychological domain, environmental domain, and general quality of life $(\rho=0.020 ; \rho=-0.164 ; \rho=0.046 ; \rho=-0.141 ; \rho=0.047 ; \rho=-0.141 ;$ respectively $)$. It means that the higher student's knowledge level, the lower their overall quality of life in a psychological and environmental domain. It suggested that in the pandemic, the student's psychological conditions are more worried and depressed about their depth understanding of COVID-19. A study conducted by Ma et al. [10] suggested that quality of life significantly correlates with depression. A person who is depressed will have a lower quality of life than those who are not depressed. This result is also supported by Qasim et al. reported that psychological conditions have a relationship with knowledge level [31]. Psychological health was associated with mental and emotional health to influence positive-negative balance, thinking, learning, memory concentration, body imaging, and self-respect. Furthermore, the person who has good knowledge about COVID-19 will have more protective behavior as an effective response in the pandemic face. Extreme self-care should lead a person to think about the stress response's potential dangers [32]. Other findings stated that stress could reduce a person's concentration. This study explained that a disease pandemic could psychologically affect a person by thinking more about the risk and health status, which impact their emotional and social behavior changes [33]. This protective behavior can be demonstrated when a person complies with government policies in controlling COVID-19 [34].

COVID-19 has influenced the environmental domain of quality of life, such as the public access to supporting health services, financial facilities, infrastructure, and recreation opportunities [35]. Considering 
these current studies, "high" knowledge respondents may not be surprised to give lower scores in environmental, leisure, and financial aspects of the quality-of-life domain. To prevent COVID-19 transmission, a knowledgeable student will comply with the university regulation about the online learning strategy. Low-income students also must strictly manage their internet quota budget to be able to participate in online learning. They also should maintain social distancing by avoiding spending their leisure time in the crowded recreation areas. The implementation of those kinds of policies will influence their quality of life [36]-[38]. Furthermore, life quality will likely improve when the pandemic is lifted under controlled [36].

Table 4. The correlation between knowledge of COVID-19 and student's quality of life

\begin{tabular}{llcc}
$\begin{array}{c}\text { Independent } \\
\text { variable }\end{array}$ & \multicolumn{1}{c}{ Dependent variable } & \multicolumn{2}{c}{ Rank Spearman Correlation Test } \\
& \multicolumn{1}{c}{ Coefficient correlation } & $\begin{array}{c}\text { p-value } \\
(* \text { significant correlation) }\end{array}$ \\
\hline & Physical domain & -0.038 & 0.589 \\
Level of & Psychological domain & -0.164 & $0.020^{*}$ \\
knowledge & Social domain & -0.120 & 0.091 \\
& Environmental domain & -0.141 & $0.046^{*}$ \\
& General quality of life & -0.141 & $0.047^{*}$ \\
& Satisfaction with health & -0.114 & 0.108 \\
\hline
\end{tabular}

Public understanding of COVID-19 during the pandemic in Indonesia has been widely studied. A study conducted by Devina et al. concluded that the respondents had a relatively good initial understanding of COVID-19 during the initial outbreak in Indonesia [35]. However, another study conducted by Maria stated that the population's quality of life of COVID-19 was worsened [16]. It can be caused by the people's awareness of the potential dangers of COVID-19, thus making them judge that their quality of health is inadequate to control the pandemic. A relationship between knowledge and community perceptions will also lead to prevent COVID-19 from affecting the quality of life [36]. Finally, self-control is needed to mediate perception and quality of life during the COVID-19 pandemic.

This study has several limitations, including the sample taken, which is less representative for the Indonesian population. It is also challenging to determine the exclusion criteria for paid leave students in the online questionnaire distribution. Therefore, further research needs to consider the larger sample with other specific criteria regarding knowledge and quality of life in obtaining more comprehensive research data.

\section{CONCLUSION}

The majority of respondents received information regarding COVID-19 from social media platforms. However, health science students have better knowledge than social science students. This study reported significant relationship between student knowledge and several domains of life quality, including psychological domain, environmental domain, and overall quality of life. This study can be used as preliminary research for the development of subsequent research models. It can also be a suggestion for the higher education authorities to pay more attention and identify policies to control the COVID-19 pandemic.

\section{ACKNOWLEDGEMENTS}

The authors thank to all of the respondents who contributed to this study. We are also grateful to Muhammadiyah Magelang University and Grant of RisetMu by Muhammadiyah Higher Education, Research and Development Council, Central Leadership of Muhammadiyah for the support in this study.

\section{REFERENCES}

[1] R. Kunjana Rahardi, "Building Critical Awareness of Corona Virus-Related News: Cyber-Pragmatic Study of COVID-19 Hoaxes on Social Media," Int. J. Adv. Sci. Technol., vol. 29, no. 6, pp. 5398-5409, 2020.

[2] Z. Xu et al., "Pathological Findings of COVID-19 Associated With Acute Respiratory Distress Syndrome," Lancet Respir. Med., vol. 8, no. 4, pp. 420-422, 2020, doi: https://doi.org/10.1016/S2213-2600(20)30076-X.

[3] S.-E. A. WHO, "COVID-19 Weekly Situation Report World Health Organization," 2020. [Online]. Available: https://www.who.int/southeastasia/outbreaks-and-emergencies/novel-coronavirus-2019.

[4] World Health Organization Indonesia, "Coronavirus Disease Situation Report World Health Organization," World Heal. Organ., no. December, pp. 1-17, 2020. [Online]. Available: https://www.who.int/indonesia. 
[5] M. Slimani, A. Paravlic, F. Mbarek, N. L. Bragazzi, and D. Tod, "The Relationship Between Physical Activity and Quality of Life During the Confinement Induced by COVID-19 Outbreak: A Pilot Study in Tunisia," Front. Psychol., vol. 11, no 1882, pp. 1-5, 2020, doi: 10.3389/fpsyg.2020.01882.

[6] M. Khosravi, "Perceived Risk of COVID-19 Pandemic: The Role of Public Worry and Trust," Electron. J. Gen. Med., vol. 17, no. 4, pp. 1-2, 2020, doi: https://doi.org/10.29333/ejgm/7856.

[7] R. Abu, A. Zaharuddin, S. Ahmad, N. Khoo, K. Seng, and R. Rodiyah, "Covid-19 Social Media Trending and Hoaxes: Malaysian Perception Index (MPI) and How Does the Law Respond to Fake News and Hoaxes ( Comparing Malaysia and Indonesia)," Law Res. Rev. Q., vol. 6, no. 3, pp. 199-206, 2020, doi: https://doi.org/10.15294/lrrq.v6i4.38456.

[8] A. Lee, "Online Hoaxes, Existential Threat, and Internet Shutdown: A Case Study of Securitization Dynamics in Indonesia," J. Indones. Soc. Sci. Humanit., vol. 10, no. 1, pp. 17-34, 2020, doi: http://dx.doi.org/10.14203/jissh.v10i1.156.

[9] S. Tasnim, M. Hossain, and H. Mazumder, "Impact of rumors and misinformation on COVID-19 in Social Media," J. Prev. Med. Public Heal., vol. 53, no. 3, pp. 171-174, 2020, doi: https://doi.org/10.3961/jpmph.20.094.

[10] Y. Ma, W. Li, H. Deng, L. Wang, Y. Wang, and P. Wang, "Prevalence of Depression and Its Association With Quality of Life in Clinically Stable Patients With COVID-19," J. Affect. Disord., vol. 275, pp. 145-148, 2020, doi: 10.1016/j.jad.2020.06.033.

[11] M. Saefi et al., "Survey data of COVID-19-related knowledge, attitude, and practices among indonesian undergraduate students," Data Br., vol. 31, no. 105855, pp. 1-5, 2020, doi: https://doi.org/10.1016/j.dib.2020.105855.

[12] M. Saefi et al., "Validating of Knowledge, Attitudes, and Practices Questionnaire for Prevention of COVID-19 infections among Undergraduate Students: A RASCH and Factor Analysis," Eurasia J. Math. Sci. Technol. Educ., vol. 16, no. 12, pp. 1-14, 2021, doi: https://doi.org/10.29333/ejmste/9352.

[13] Y. A. Rias et al., "Effects of Spirituality, Knowledge, Attitudes, and Practices toward Anxiety Regarding COVID19 among the General Population in INDONESIA: A Cross-Sectional Study,” J. Clin. Med., vol. 9, no. 12, pp. 216, 2020, https://doi.org/10.3390/jcm9123798.

[14] S. Sulistyawati et al., "Knowledge, attitudes, practices and information needs during the covid-19 pandemic in indonesia," Risk Manag. Healthc. Policy, vol. 14, pp. 163-175, 2021, doi: http://doi.org/10.2147/RMHP.S288579.

[15] R. O. Nanda, L. Lolita, W. Indayati, I. Rusdiyanti, and A. Ikhsanudin, "Knowledge , precautionary actions , and perceived risk of COVID-19 among Indonesian people," Int. J. Public Heal. Sci., vol. 10, no. 1, pp. 8-15, 2021, doi: http://doi.org/10.11591/ijphs.v10i1.20589.

[16] M. E. Melo-Oliveira et al., "Reported quality of life in countries with cases of COVID19: a systematic review," Expert Rev. Respir. Med., vol. 15, no. 2, pp. 213-220, 2021, doi: https://doi.org/10.1080/17476348.2021.1826315.

[17] B. L. Zhong et al., "Knowledge, attitudes, and practices towards COVID-19 among chinese residents during the rapid rise period of the COVID-19 outbreak: A quick online cross-sectional survey," Int. J. Biol. Sci., vol. 16, no. 10, pp. 1745-1752, 2020, doi: https://dx.doi.org/10.7150\%2Fijbs.45221.

[18] H. Alzoubi, N. Alnawaiseh, A. Al-Mnayyis, M. Abu-Lubad, A. Aqel, and H. Al-Shagahin, "COVID-19 Knowledge, attitude and practice among medical and non-medical university students in Jordan," J. Pure Appl. Microbiol., vol. 14, no. 1, pp. 17-24, 2020, doi: 10.22207/JPAM.14.1.04.

[19] World Health Organization, "WHOQOL-BREF versi Indonesia," World Heal. Organ. Qual. Life (WHOQOL-BREF ), pp. 1-5, 2004. https://www.who.int/substance_abuse/research_tools/en/indonesian_whoqol.pdf.

[20] K. Kistan, S. Malka, and M. Musni, "The Relationship Between Knowledge, Attitude, And Readiness of Academic Community in Covid-19 Spread Prevention: Batari Toja Nursing Academy, Watampone," Int. J. Heal. Med. Sci., vol. 3, no. 1, p. 72, 2020, doi: https://dx.doi.org/10.31295/ijhms.v3n1.155.

[21] J. Sahar, S. M. Kiik, W. Wiarsih, and U. Rachmawati, "Coronavirus Disease-19: Public Health Nurses' Knowledge, Attitude, Practices, and Perceived Barriers in Indonesia," Open Access Maced. J. Med. Sci., vol. 8, no. T1, pp. 422-428, 2020, doi: https://doi.org/10.3889/oamjms.2020.5446.

[22] A. I. Khasawneh et al., "Medical Students and COVID-19: Knowledge, Attitudes, and Precautionary Measures. A Descriptive Study From Jordan," Front. Public Heal., vol. 8, no. 253, pp. 1-9, 2020, doi: https://dx.doi.org/10.3389\%2Ffpubh.2020.00253.

[23] A. Fauzi, H. Husamah, F. J. Miharja, D. Fatmawati, and T. I. Permana, "Exploring COVID-19 Literacy Level among Biology Teacher Candidates," EURASIA J. Math. Sci. Technol. Educ., vol. 16, no. 7, pp. 1-13, 2020, https://doi.org/10.29333/ejmste/8270.

[24] Z. Wang and K. Tang, "Combating COVID-19: health equity matters," Nat. Med., vol. 26, no. 4, p. 2020, 2020, doi: https://doi.org/10.1038/s41591-020-0823-6.

[25] D. A. González-padilla, "Social media influence in the COVID-19 Pandemic," Int Braz, vol. 46, no. Suppl 1, pp. 120-124, 2020, doi: 10.1590/S1677-5538.IBJU.2020.S121.

[26] I. H. Wardanie, "Hoax Law Enforcement During Covid 19 Pandemic In Indonesia," J. Liga Huk., vol. 1, no. 1, pp. 129-135, 2020, doi: https://doi.org/10.1590/s1677-5538.ibju.2020.s121.

[27] L. Gupta, A. Y. Gasparyan, D. P. Misra, V. Agarwal, O. Zimba, and M. Yessirkepov, "Information and misinformation on COVID-19: A cross-sectional survey study," J. Korean Med. Sci., vol. 35, no. 27, pp. 1-11, 2020, https://dx.doi.org/10.3346\%2Fjkms.2020.35.e256.

[28] World Health Organization Indonesia, "Mythbuster," 2020. [Online]. Available: https://www.who.int/indonesia/news/novel-coronavirus/mythbusters

[29] C. Wang, R. Pan, X. Wan, Y. Tan, L. Xu, and R. S. Mcintyre, "Mask use during COVID-19: A risk adjusted strategy," Environ. Pollut., vol. 266, no.115099, pp. 1-6., 2020,doi: https://doi.org/10.1016/j.envpol.2020.115099. 
[30] J. Kumar et al., "Knowledge, Attitude, and Practices of Healthcare Workers Regarding the Use of Face Mask to Limit the Spread of the New Coronavirus Disease (COVID-19)," Cureus, vol. 12, no. 4, pp. 2-8, 2020, https://doi.org/10.1016/j.envpol.2020.115099.

[31] M. Qasim, U. A. Awan, M. S. Afzal, M. A. N. Saqib, S. Siddiqui, and H. Ahmed, "Dataset of knowledge, attitude, practices and psychological implications of healthcare workers in Pakistan during COVID-19 pandemic," Data Br., vol. 32, no.106234, pp. 1-7, 2020, doi: https://doi.org/10.1016/j.dib.2020.106234.

[32] Z. Wang, H. Yang, Y. Yang, D. Liu, Z. Li, and X. Zhang, "Prevalence of anxiety and depression symptom, and the demands for psychological knowledge and interventions in college students during COVID-19 epidemic: A large cross-sectional study," J. Affect. Disord., vol. 275, no. 106234, pp. 188-193, 2020, doi: https://doi.org/10.1016/j.jad.2020.06.034.

[33] M. W. Gallagher, M. J. Zvolensky, L. J. Long, A. H. Rogers, and L. Garey, "The Impact of Covid - 19 Experiences and Associated Stress on Anxiety, Depression, and Functional Impairment in American Adults," Cognit. Ther. Res., vol. 44, no. 6, pp. 1043-1051, 2020, doi: https://doi.org/10.1007/s10608-020-10143-y.

[34] S. Galea, R. Merchant, and N. Lurie, "TheMental Health Consequences ofCOVID-19 and Physical Distancing," Am. Med. Assoc., vol. 180, no. 6, pp. 817-818, 2020, doi: 10.1001/jamainternmed.2020.1562.

[35] F. Pulvirenti et al., "Health-Related Quality of Life in Common Variable Immunodeficiency Italian Patients Switched to Remote Assistance During the COVID-19 Pandemic," J. Allergy Clin. Immunol. Pract., vol. 8, no. 6, pp. 1894-1899.e2, 2020, doi: https://doi.org/10.1016/j.jaip.2020.04.003.

[36] P. G. de B. Silva et al., "Distance learning during social seclusion by COVID-19: Improving the quality of life of undergraduate dentistry students," Eur. J. Dent. Educ., vol. 21, no. 1, pp. 1-11, 2020, , doi: https://doi.org/10.1111/eje.12583.

[37] K. Riiser, S. Helseth, K. Haraldstad, A. Torbjørnsen, and K. R. Richardsen, “Adolescents' health literacy, health protective measures, and health-related quality of life during the Covid-19 pandemic," PLoS One, vol. 15, no. 8, pp. 1-13, 2020, doi: https://doi.org/10.1371/journal.pone.0238161.

[38] C. Wenjun et al., "The psychological impact of the COVID-19 epidemic on college students in China," Psychiatry Res., vol. 287, no. 112934, pp. 1-5, 2020, doi: https://doi.org/10.1016/j.psychres.2020.112934 